\title{
Um breve estudo sobre a composição de Dom Quixote das crianças (1936), de Monteiro Lobato ${ }^{1}$
}

\author{
A brief studyon the composicion of Dom Quixote das crianças (1936), by
}

Monteiro Lobato

Patrícia A. Beraldo ROMANO*

Universidade Federal do Sul e Sudeste do Pará (UNIFESSPA)

\begin{abstract}
RESUMO: Publicada em 1936, pela Companhia Editora Nacional, Dom Quixote das Crianças teve uma primeira edição com 10.625 exemplares, número bastante expressivo para a época em que a obra foi publicada. Em 1940, quando sai a publicação da segunda edição, esse número cai para 5025 exemplares, mas ainda significativo para o Brasil de leitores daquele momento. As ilustrações de Gustave Doré, presentes na tradução portuguesa do século XIX, feita pelos viscondes de Castilho e de Azevedo, foram mantidas por Lobato na primeira edição de seu texto, apesar de, mais tarde, serem abandonadas, talvez por problemas com direitos autorais. Em 1947, na edição das obras completas, o ilustrador já era André Le Blanc. Este trabalho pretende apresentar algumas discussões sobre a constituição da obra Dom Quixote das Crianças e, para isso, se serve de teóricos como Amaya Prado (2008), Whitaker Penteado (1997), Silvia Cobelo
\end{abstract} (2010), Magno Silveira (2015), dentre outros.

PALAVRAS-CHAVES: Dom Quixote das Crianças. Leitores. Dom Quixote.

ABSTRACT: Published in 1936, by the National Publishing Company, Dom Quixote das Crianças had a first edition with 10.625 copies, quite a number expressive for the time in which the work was published. In 1940, when publishing the second edition, this number drops to 5025 copies, but still significant for Brazil of readers of that time. The illustrations of Gustave Doré, present in the Portuguese translation of the nineteenth century, by the viscounts of

\footnotetext{
${ }^{1} \mathrm{O}$ texto em questão é parte adaptada de um capítulo de nossa tese intitulada Dona Benta: mediadora de leitura em Dom Quixote das Crianças e em Geografia de Dona Benta, de Monteiro Lobato, defendida em fevereiro de 2017 no Programa de Pós-Graduação em Letras da Universidade Presbiteriana Mackenzie, sob a orientação da professora Dra. Marisa Lajolo. Parte do capítulo também está publicada na obra Dona Benta: uma mediadora no mundo da leitura (2019).

* Patrícia A. Beraldo Romano é doutora em Letras pela Universidade Presbiteriana Mackenzie (2017) e atualmente é professora de Literatura Infantojuvenil e Estágio Supervisionado na UNIFESSPA, campus de Marabá, atuando na Graduação e na Pós-Graduação. Email para contato: paromano@ unifesspa.edu.br
}

Revista Moara, n. 52, jan-jul 2019 ISSN: 0104-0944

Recebido em 10/04/2019

Avaliado em 08/05/2019 
Castilho and Azevedo, were maintained by Lobato in the first edition of his text, although later abandoned, perhaps due to copyright problems. In 1947, in the edition of the complete works, the illustrator was already André Le Blanc. This work intends to present some discussions about the constitution of Dom Quixote das Crianças and, for this, it uses theorists such as Amaya Prado (2008), Whitaker Penteado (1997), Silvia Cobelo (2010), Magno Silveira (2015), among others.

Keywords: Dom Quixote das Crianças. Readers. Dom Quixote.

Dom Quixote das crianças foi publicado por Monteiro Lobato em 1936, pela Companhia Editora Nacional. De acordo com Amaya Prado (2008) em "Dom Quixote das crianças e de Lobato", houve uma tiragem de 10.625 exemplares na primeira edição e de 5.025 na segunda, em 1940. Houve, até hoje, 27 edições. Segundo Whitaker Penteado (1997, p. 197), a primeira edição teria contado com as antigas ilustrações de Gustave Doré, "mas provavelmente os problemas de qualidade de impressão -ou de direitos autorais- fizeram com que fossem, mais tarde abandonadas". A informação de Penteado não nos esclarece quantas edições foram editadas com as ilustrações de Doré, o que sabemos é que na edição completa, de 1947, o ilustrador já era André Le Blanc.

Gustave Doré nasceu em 1832, em Estrasburgo, na França, e produziu ilustrações para obras, em especial, para as consideradas obras-primas; essas ilustrações deveriam "falar" junto com o texto, nos informa Ana Beatriz de Araújo Linardi (2007, p.4 $)^{2}$, em artigo sobre Doré e Dali. A autora ainda nos lembra que:

Doré dominou a arte da gravura popular do século XIX. Seu desenho preciso, detalhista e sua grande capacidade de manipular texturas e matizes, conseguiu imprimir uma atmosfera quase sobrenatural por meio de jogos fascinantes de luz e sombra. [...] A ilustração de Dom Quixote para Doré foi um desafio. Para conseguir realizar o que ele considerava uma síntese da obra, em 1863 produziu 375 desenhos, que se dividem ao longo do livro [...]. Doré transpõe, [...] a quase totalidade de informações que o texto fornece na apresentação e contextualização do personagem, com uma precisão documental. Como o artista almejava realizar uma síntese da obra em imagens, da maneira como ele a ilustrou podemos fazer uma leitura somente através delas, como se fossem parte de um story-board ${ }^{3}$ que antecipa a filmagem de uma sequência cinematográfica

\footnotetext{
${ }^{2}$ Disponível em: https://www.ifch.unicamp.br/eha/atas/2007/LINARDI,\%20Ana\%20Beatriz\%20de\%20Araujo.pdf. Acesso $16 / 06 / 2016$.

${ }^{3}$ Sucessão de desenhos que sintetizam os planos de uma determinada sequência fílmica (nota da autora).
}

Revista Moara, n. 52, jan-jul 2019 ISSN: 0104-0944

Recebido em 10/04/2019

Avaliado em 08/05/2019 
Além disso, Linardi (2007, p.4) também nos informa que "nenhum outro artista imprimiu sua marca em uma personagem literária como Doré ao Dom Quixote" e essa “imagem" ficaria consagrada no imaginário popular.

Talvez tenha sido o fascínio por uma edição como essa, que reproduzia todas as ilustrações de Doré, o motivo que levou a boneca Emília a invadir a biblioteca de Dona Benta em busca do livrão de Cervantes. Além disso, podemos acrescentar a grande extensão dos dois volumes da obra e sua localização nas prateleiras mais altas da biblioteca de Dona Benta, indício de textos raros e importantes, que chamam a atenção da bonequinha de pano, interessada por "livros de figuras". Depois de conseguir com o visconde uma alavanca para a retirada dos livros-tijolos, os dois volumes de Dom Quixote, de Cervantes (1876), despencam da estante sobre o pobre boneco de milho, amassando-o. Emília parece pouco se importar com o acidente, restringindo-se a guardar em um vidro apenas o caldo da ciência que dele saíra.

Abre o primeiro volume e já na primeira página a boneca incomoda-se com o duplo "a" de Saavedra, sobrenome de Cervantes. Corta, com um lápis, um dos "as". Embalada pela beleza das imagens de Doré, Emília começa a folhear a obra. Nesse momento, Dona Benta entra na biblioteca e vê a bagunça feita pela criatura de pano. Quer explicações. “A culpa é da alavanca”, justifica-se a boneca. Resta a Tia Nastácia relatar o ocorrido à sinhá. Nessa mesma noite, depois desse incidente, Dona Benta começa a leitura da obra de Cervantes para a garotada.

Temos aqui, logo na abertura de Dom Quixote das Crianças, de Monteiro Lobato, uma breve discussão sobre a composição da obra a partir da curiosidade de Emília. O leitor de Lobato fica sabendo que o livro da biblioteca de Dona Benta é muito grande e, por isso, o texto está dividido em dois volumes. Também descobre seu famoso ilustrador francês do século XIX, Gustave Doré (1832-1883), e saberá que se trata de uma tradução portuguesa, feita por dois viscondes, Castilho e Azevedo. E aqui, abrimos um parênteses para algumas curiosidades que contribuem para o leitor entender um pouco melhor a composição do texto de Lobato.

Em pesquisa feita no Centro de Documentação Alexandre Eulálio (CEDAE)/UNICAMP, descobrimos, no Fundo Monteiro Lobato, existente desde 2000, no item referente a obras que foram doadas pela família e pertenciam à biblioteca do autor, dois volumes de $O$ engenhoso fidalgo Dom Quixote de La Mancha, de Miguel de Revista Moara, n. 52, jan-jul 2019 ISSN: 0104-0944 
Cervantes Saavedra, edição de 1876, tradução portuguesa dos viscondes de Castilho e de Azevedo e com os desenhos de Gustave Doré. Chamou-nos a atenção a presença dessa obra, em dois volumes grossos e em formato grande, tal qual o narrador a menciona no livro infantil lobatiano. A título de curiosidade, apresentamos aqui algumas imagens desses livros e algumas ilustrações de Doré neles presentes.

Figura 1: CERVANTES, Miguel de. O Engenhoso Fidalgo Dom Quixote de La Mancha. Ilustrações de Gustave Doré. Trad. Viscondes De Castilho e Azevedo. Porto: Imprensa da Cia Litteraria, 1876,

2 vol. UNICAMP/IEL/CEDAE MLB 800014.

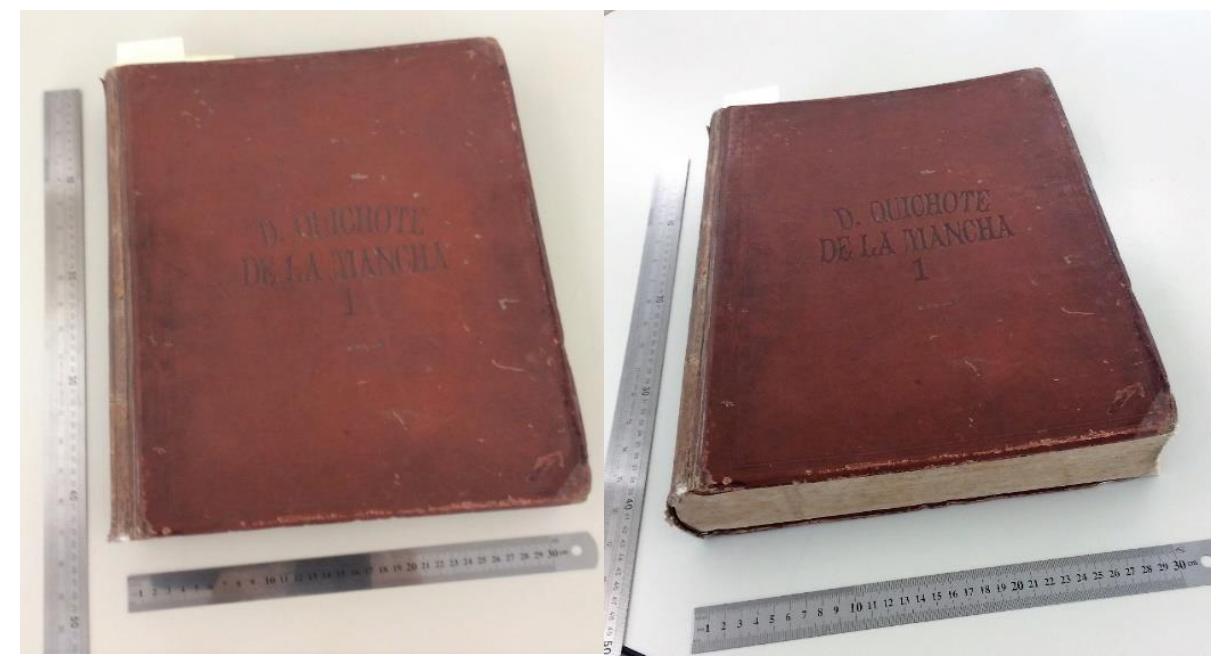

Figura 2: CERVANTES, Miguel de. O Engenhoso Fidalgo Dom Quixote de La Mancha. Ilustrações de Gustave Doré. Trad. Viscondes de Castilho e Azevedo. Porto: Imprensa da Cia Litteraria, 1876, vol 1, p. folha de rosto e ilustração que a antecede. 


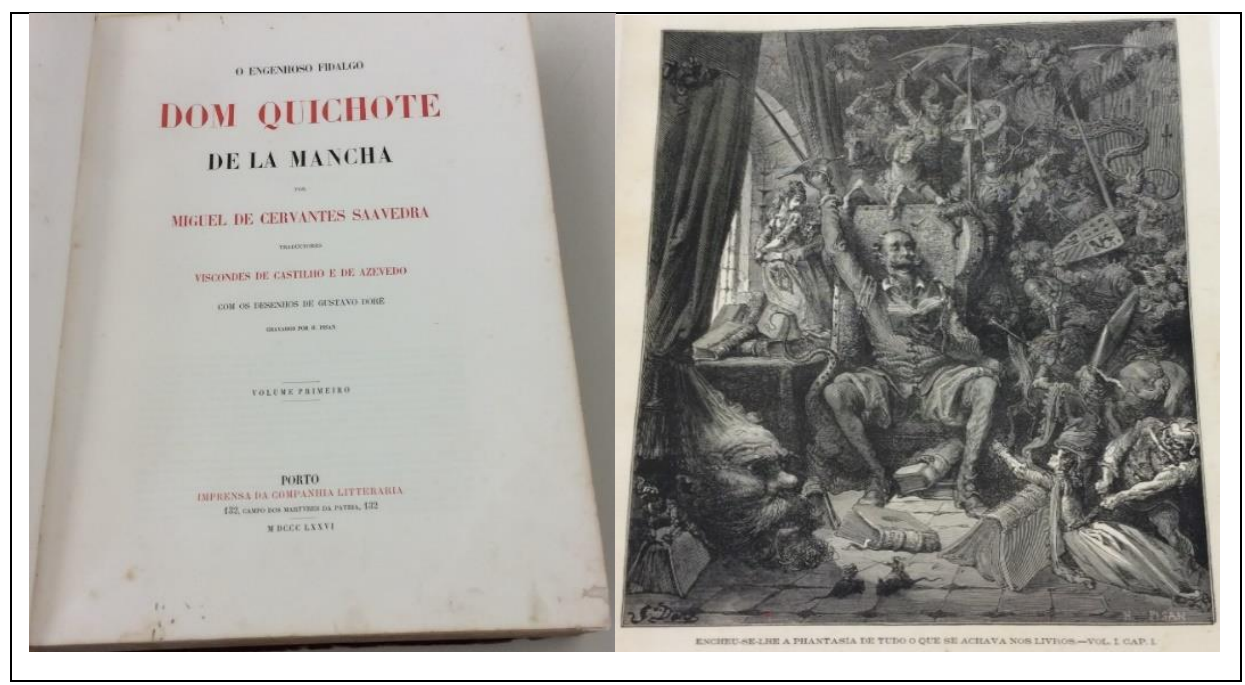

Fonte: Cervantes (1876, v.1)

Figura 3: CERVANTES, Miguel de. O Engenhoso Fidalgo Dom Quixote de La Mancha. Ilustrações de Gustave Doré. Trad. Viscondes de Castilho e Azevedo. Porto: Imprensa da Cia Litteraria, 1876, vol 1, ilustração entre as páginas 110 e 111 e ilustração entre as páginas 222 e 223.

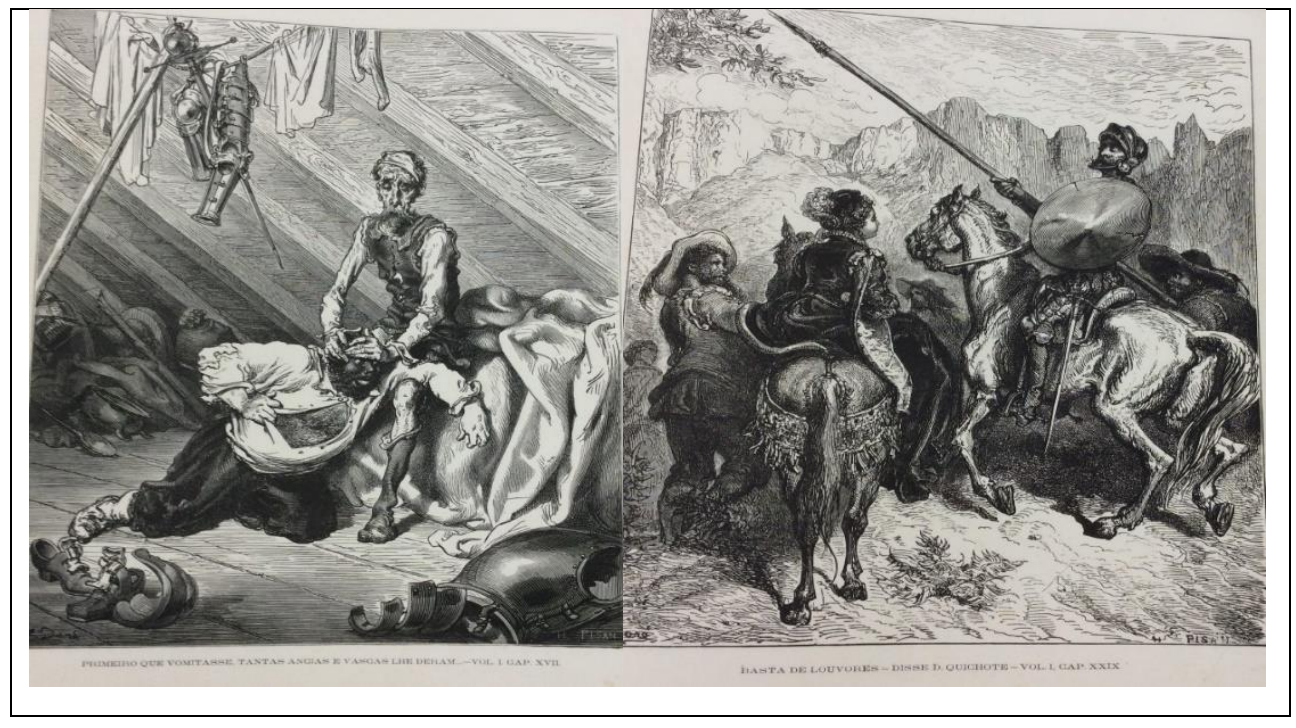

Figura 4 - Foto do livro Dom Quixote de La Manch: vol. 1 e vol.2 da UNICAMP/IEL/CEDAE e MLB 800014

Revista Moara, n. 52, jan-jul 2019 ISSN: 0104-0944

Recebido em 10/04/2019

Avaliado em 08/05/2019 


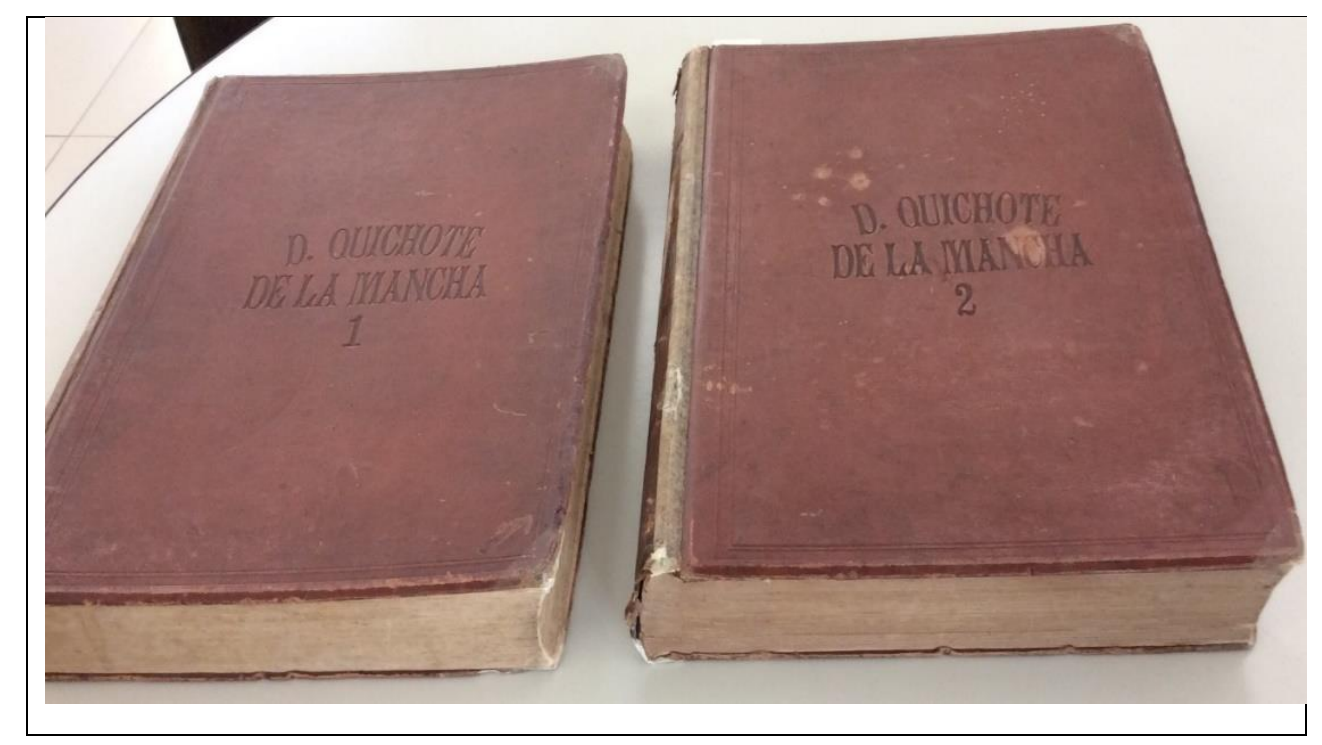

A tradução desses dois volumes que pertenceram a Monteiro Lobato foi feita pelos Viscondes de Castilho e Azevedo, como a que Dona Benta faz referência também em Dom Quixote das Crianças. Na obra, pertencente à biblioteca lobatiana, temos ainda um prefácio feito pelo escritor, romancista e poeta português, Pinheiro Chagas. Segundo Silvia Cobelo (2010), que estudou os tradutores de Dom Quixote no Brasil, essa é a primeira tradução assinada em português da obra cervantina e a que tem mais publicações, até hoje, em língua portuguesa. Ficou conhecida conforme nomeada por Dona Benta, a tradução “dos Viscondes", mas, segundo a estudiosa, inicia talvez "uma tradição de injustiças editoriais e omissões de créditos autorais nas traduções do Quixote, algo que perdura nas edições publicadas da obra até hoje" (COBELO, 2010, p. 8).

A referência diz respeito, possivelmente, à tradução de Pinheiro Chagas, que não é citado como tradutor, mas que teria feito, segundo Cobelo (2010), a tradução de praticamente todo o segundo volume em virtude da morte dos viscondes e, sequer, é lembrado no prefácio que também fez à obra, mas que poucas vezes foi reproduzido nas edições. Por sua vez, o visconde de Castilho, Antônio Feliciano de Castilho (18001875), foi o primeiro a traduzir o texto. Sua morte ocorreu em 1875, um ano antes de finalizado o trabalho de tradução. Assim, o primeiro volume seria terminado pelo Visconde de Azevedo.

Francisco Lopes de Azevedo Velho de Fonseca Barbosa Pinheiro Pereira e Sá Coelho (1809-1876), nos informa ainda Cobelo (2010), foi quem assumiu a tradução do 
Quixote após a morte do visconde de Castilho e teria, provavelmente, terminado a tradução do primeiro volume do texto cervantino, já que também viria a falecer no ano seguinte, 1876, quando o primeiro livro foi lançado. O terceiro e último tradutor teria sido, conforme nos informa Cobelo (2010), citando Maria Fernanda de Abreu (1994), Manuel Pinheiro Chagas (1842-1895), jornalista e escritor, que também fez o prefácio existente na edição da biblioteca lobatiana que, segundo Cobelo (2010), tem sido negligenciado em várias reedições.

Há também certa curiosidade apontada pela estudiosa de que essa tradução portuguesa foi publicada no Brasil em 1942/43 ${ }^{4}$ e muitas editoras preferiam essa a uma feita por tradutores brasileiros, talvez porque não fosse necessário pagar os direitos autorais. Enfim, fica aqui justificada a importância atribuída a essa obra por Dona Benta no texto infantil lobatiano: trata-se, de fato, de um texto primoroso e que deveria ser respeitado. Tal texto, para a senhora avó, poderia ser motivo de leitura efetiva das crianças no futuro quando fossem, talvez, leitores mais proficientes. Explicações dadas sobre os "livrões", fechamos nossos parênteses e voltamos ao momento em que Emília rasurara o texto de Cervantes.

Dona Benta repreende a boneca de pano por ter rasurado obra rara, que deveria ser, no mínimo, respeitada por sua importância e tradição. Entretanto, a repreensão era educadora e buscava ensinar Emília a respeitar o texto clássico e raro.

\footnotetext{
[...] -Quem riscou o segundo $a$ de Saavedra?

-Fui eu -disse Emília.

-Por quê?

-Porque sou inimiga pessoal da tal ortografia velha coroca que complica a vida da gente com coisas inúteis. Se um $a$ diz tudo, para que dois?

-Mas você devia respeitar esta edição, que é rara e preciosa. Tenha lá as ideias que quiser, mas acate a propriedade alheia. Esta edição foi feita em Portugal há muitos anos. Nela aparece a obra de Cervantes traduzida pelo famoso Visconde de Castilho e pelo Visconde de Azevedo (LOBATO, 1957, p. 15).
}

Ainda sobre a constituição do texto de Lobato (1957), no início do segundo capítulo, há um aviso ao leitor sobre a necessidade de se ter uma "armação de tábuas", feita por Pedrinho, para Dona Benta apoiar o livro enquanto conta a história. Mas conta qual história e como conta? Se o "livrão" não se acomoda facilmente nas mãos, a

\footnotetext{
${ }^{4}$ A edição de Monteiro Lobato é portuguesa.

Revista Moara, n. 52, jan-jul 2019 ISSN: 0104-0944
}

Recebido em 10/04/2019

Avaliado em 08/05/2019 
linguagem dos tradutores parece que também não conquista os jovens leitores. Essas questões passam a nos interessar agora.

Dom Quixote das Crianças já não é Dom Quixote, de Miguel de Cervantes. Lobato parece ter se interessado muito, ao longo de sua vida de escritor, por tradução de textos para seus pequenos leitores. Além de ganhar dinheiro com essas traduções e viver disso, ele tentava traduzir e adaptar o texto ao gosto e sabor da realidade do pequeno leitor brasileiro. Lobato falava sobre tradução também com o amigo Rangel, em carta de 11/01/1925 apud LOBATO (1956b. Nela, lembra que havia bastantes textos a serem traduzidos e explicava como deveria ser a linguagem desse trabalho ao amigo. Ele pretendia refazer traduções portuguesas e também muitas expedidas pela Casa Francesa Garnier que, para ele, não facilitavam na linguagem para o pequeno leitor brasileiro. Além disso, também queria investir em traduções de textos, em especial, em inglês. Vejamos em carta a Rangel de 11/01/1925:

Traduzirás uns três, à escolha, e mos mandarás com o original; quero aproveitar as gravuras. Estilo água do pote, hein? E ficas com liberdade de melhorar o original onde entenderes. O Dom Quixote é para ver se vale a pena traduzir. [...] Lembra-te que os leitores vão ser todos os Nelos ${ }^{5}$ deste país e escreve como se estivesse escrevendo para o teu. Estou a examinar os Contos de Grimm dados pelo Garnier. Pobres crianças brasileiras! Que traduções galegais! Temos de refazer tudo isso -abrasileirar a linguagem (LOBATO, 1956b, p. 275) ${ }^{6}$.

Como editor, contribuiu para dessacralizar o livro numa época em que isso ainda incomodava a maioria dos escritores e continua incomodando, até os dias atuais, já que uma parte da crítica literária ainda vê o bom escritor como aquele que não escreve para vender, mas para ser imortalizado. Em carta a Rangel, de 17/01/1920, vemos o que o editor-Lobato pensava a esse respeito: “Tens toda e não tens nenhuma razão. Tens-na no meu caso: não sou literato, não pretendo ser, não aspiro a louros acadêmicos, glórias, bobagens. Faço livros e vendo-os porque há mercado para a mercadoria” (LOBATO, 1956b, p. 211). Embora possa parecer uma maneira bastante fria de encarar a profissão de editor e de escritor, Lobato não abria mão da qualidade de seu texto, como podemos constatar também nas suas obras infantis.

A primeira aparição do desejo de traduzir Cervantes ocorreu em carta de 1921. Nela insistia que o amigo continuasse traduzindo contos de Shakespeare "em linguagem

\footnotetext{
${ }^{5}$ Nelo era o nome do filho de Godofredo Rangel.

${ }^{6}$ Edgard Cavalheiro fala em 82 obras traduzidas por Lobato, no livro Monteiro Lobato: vida e obra.
} 
bem simples, sempre na ordem direta e com toda a liberdade" (LOBATO, 1956b, p. 232). Ao final, lembrava: "Quanto ao D. Quixote, vou ver se acho a edição de Jansen". Ainda em 1921, quando começava a traduzir vários clássicos para crianças, comentava com Rangel (17/06/1921) que precisava de ajuda para as traduções e queria "reescrever [tudo] em língua desliteraturizada, [...] com mais leveza e graça de língua” (LOBATO, 1956b, p. 233).

Em 16/06/1934, temos comentário sobre seu prazer por traduzir:

Gosto imenso de traduzir certos autores. É uma viagem por um estilo. E traduzir Kipling, então? Que esporte! Que alpinismo! Que delícia remodelar uma obra d'arte em outra língua! Estou agora a concluir um Jack London, que alguém daqui traduziu massacradamente. Adoro London com suas neves do Alaska, com o seu Klondike, com os seus maravilhosos cães de trenó (LOBATO, 1956b, p. 327-328).

Esse desejo por traduzir excluindo as literatices e valendo-se de uma linguagem "água de pote" (11/01/1925) fazia com que suas traduções se tornassem, praticamente, adaptações, já que acabavam por ganhar um estilo quase "brasileiro". Dom Quixote das crianças passava a ser a tradução adaptada por Dona Benta para seus ouvintes que, ao participarem da história, com dúvidas, perguntas e críticas, contribuíam para o surgimento de uma nova obra, no caso, para as crianças. Não temos mais apenas a história de Dom Quixote, mas sim a história das crianças do sítio que escutam a história de Dom Quixote contada e mediada por Dona Benta e opinam sobre ela.

Assim, poderíamos pensar que o espaço de todas as aventuras do Cavalheiro da Mancha se ampliava para o espaço do Sítio do Picapau Amarelo e ambos se firmavam em constante diálogo (JUSTO, 2006). Essa é uma diferença bastante significativa entre os outros textos de Lobato que também são traduções, mas sem a presença da turma do sítio. Lembramos que isso também ocorre em Peter Pan, conforme recorda Adriana Silene Vieira em sua dissertação de mestrado (1998) intitulada Um inglês no sítio de Dona Benta: estudo da apropriação de Peter Pan na obra infantil lobatiana. Tanto em Peter Pan como em Dom Quixote das crianças a presença de Dona Benta se faz primordial. É ela quem executa o papel de mediação entre o texto literário e seus ouvintes. Lembrando aqui a tríade de Antônio Candido, autor, obra, público, poderíamos assim pensar em relação a Dom Quixote das Crianças: 


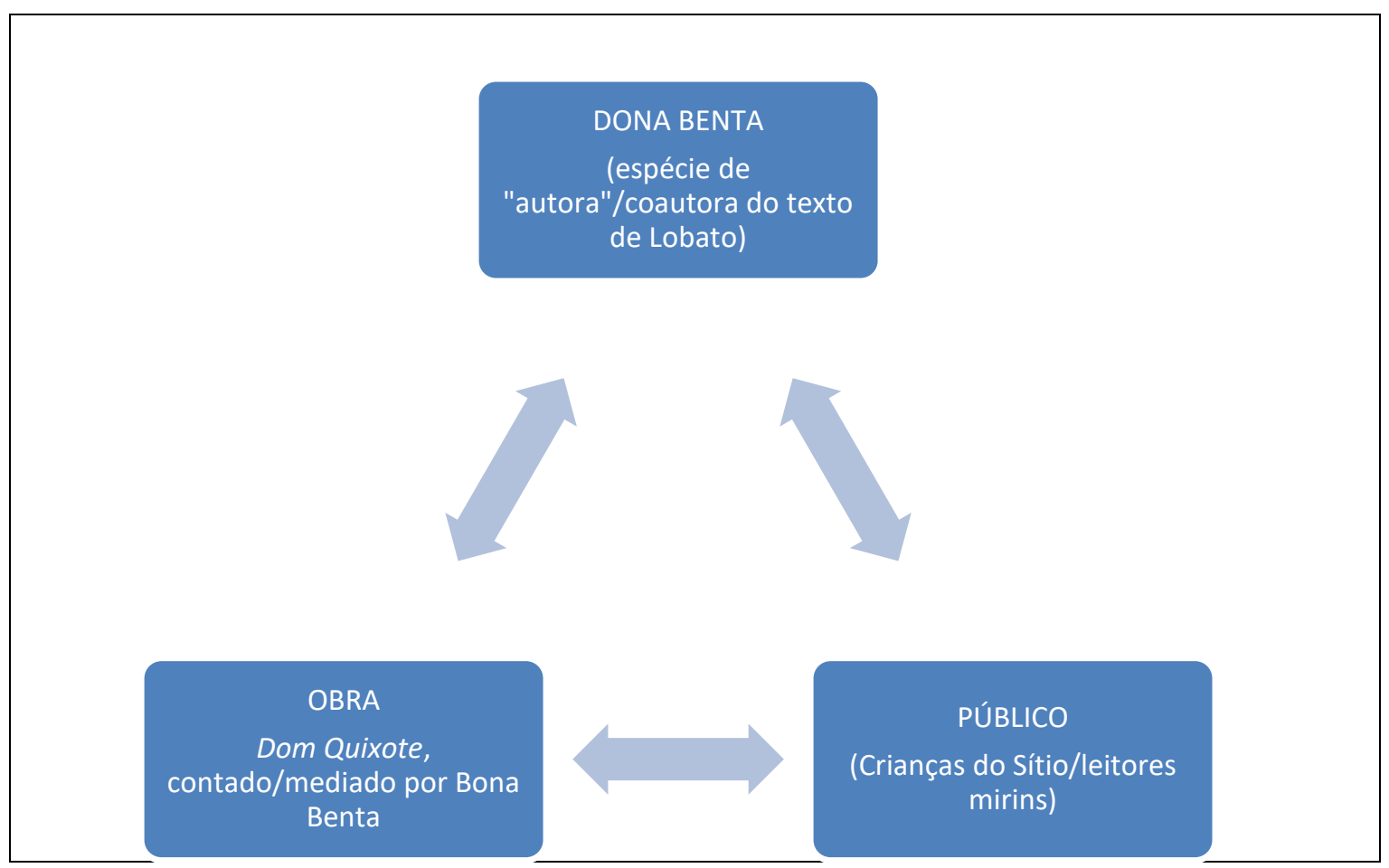

Fonte: A autora

Na primeira edição de Dom Quixote das Crianças, de 1936, da Companhia Editora Nacional, temos um subtítulo acrescentado à obra: "Contado por Dona Benta". Na edição de 1947, editada pela Editora Brasiliense, continuamos com o subtítulo e ele reaparece dez anos depois, em 1957, pela mesma editora (imaginamos que nesse intervalo ele continuou a existir nas reedições). Mas em 1977, já não temos mais o subtítulo. Procuramos encontrar edições nesse intervalo de 1957 a 1977 para procurar entender quando o subtítulo desaparece, mas não encontramos nenhuma. Apenas vimos edições posteriores a 1977 e nelas não mais temos o subtítulo, nem mesmo na edição comemorativa do centenário de nascimento de Lobato, em 1982. Acreditamos que em virtude de o título já sugerir uma adaptação, o subtítulo tenha sido excluído pela editora Brasiliense.

Assim temos o Dom Quixote, texto de Cervantes, traduzido para o português de Portugal pelos viscondes, que, por sua vez, é traduzido por Lobato, transformando-se no texto Dom Quixote das Crianças, cuja adaptação é feita através da contação da história do cavalheiro da Mancha por Dona Benta para seus netos. Ela é a conhecedora do texto cervantino e a responsável por levar a obra literária, oralmente, até as crianças do Sítio. 
Dom Quixote das crianças é considerada uma obra, segundo Penteado (1997), de adaptação literária, ao lado de Fábulas (1922), Aventuras de Hans Staden (1927), Peter Pan (1930) e Histórias de Tia Nastácia (1937). Em todas essas obras, mesmo na última, cujo título acentua a presença da personagem narradora, Dona Benta tem uma importância singular. É ela sempre quem faz a mediação dos textos de literatura para os ouvintes, a turma do Sítio.

Parece ser, todavia, em Dom Quixote das crianças, que encontramos o processo de mediação ocorrendo em sua plenitude. É nessa obra que acreditamos existir o projeto de leitura de Lobato com suas adaptações de textos literários: formar leitores críticos capazes de lerem os clássicos da literatura no futuro, caso se tornem leitores competentes. Fica assim sugerida também a questão sobre se é bom ou não apresentar os clássicos da literatura às crianças. Para Lobato, parece-nos que sim, mas numa linguagem que lhes seja palatável e digerível, que lhes propicie gosto, prazer e curiosidade para chegar, finalmente, ao texto original.

Dona Benta, dessa forma, não desqualifica o original, pelo contrário, seu trabalho de mediação e adaptação das aventuras do Cavalheiro da Mancha e de seu escudeiro contribui para que a linguagem do texto por ela oferecido atinja seu público ouvinte e desperte nele o desejo por conhecer o clássico de Cervantes.

Nesse "projeto de leitura", possivelmente presente nesta obra, Dona Benta tem papel fundamental. Temos de lembrar aqui que ela é uma personagem de seu tempo, ligada, inclusive, às situações corriqueiras vividas na década de 30 do século $\mathrm{XX}$, no Brasil, como a presença, ainda, de avós contadoras de histórias nas famílias brasileiras. Hoje é possível que as avós contemporâneas não sejam mais repositórios vivos de experiências literárias como era Dona Benta. Mesmo assim, é possível ainda nos espelharmos nela como uma personagem exemplar de contação e mediação de leitura.

Assim, em Dom Quixote das Crianças, temos um texto adaptado para o mundo infantojuvenil a partir de um clássico da literatura universal e esperamos, assim como Dona Benta, que o jovem leitor, um dia leitor proficiente, possa chegar até Dom Quixote, de Cervantes, com prazer por ter tomado contato, anteriormente, com a contação do clássico, por nossa avó mediadora de leitura.

\section{REFERÊNCIAS}

Revista Moara, n. 52, jan-jul 2019 ISSN: 0104-0944

Recebido em 10/04/2019

Avaliado em 08/05/2019 
CERVANTES, Miguel de. O Engenhoso fidalgo Dom Quixote de La Mancha. Ilustrações de Gustave Doré. Tradução de Viscondes de Castilho e Azevedo. Porto: Imprensa da Cia Litteraria, 1876. 2 vol. (MLB/CEDAE/IEL/UNICAMP).

COBELO, Silvia. Os tradutores do Quixote publicados no Brasil. In: Tradução em Revista, 2010/1, p. 1-36. Disponível em: www.maxwel.vrac.puc-rio.br. Acesso em: $16 / 06 / 2016.0 k$

JUSTO, Rosa Maria Oliveira. Os moinhos de vento no Brasil: uma leitura da adaptação de Dom Quixote das Crianças, de Monteiro Lobato. Dissertação (Mestrado em Língua Espanhola e Literaturas Espanhola e Hispano-americana). Departamento de Letras Modernas da Faculdade de Filosofia, Letras e Ciências Humanas da Universidade de São Paulo, USP, São Paulo, 2006.ok

LINARDI, Ana Beatriz de Araújo. Dom Quixote, Doré e Dali: em torno do livro ilustrado. Disponível em: http://alb.org.br/arquivomorto/edicoes_anteriores/anais16/sem14pdf/sm14ss03_01.pdf. Acesso em:16/06/2016.ok

LOBATO, Monteiro. A barca de Gleyre. São Paulo: Brasiliense, 1956a. $1^{\circ}$ tomo. ok LOBATO.Monteiro. A barca de . São Paulo: Brasiliense, 1956b. $2^{\circ}$ tomo.

Dom Quixote das Crianças: contado por Dona Benta. Ilustrações de André Le Blanc. 7. ed. São Paulo: Brasiliense, 1957.

PENTEADO, J. Roberto Whitaker. Os Filhos de Lobato: o imaginário infantil na ideologia do adulto. Rio de Janeiro: Qualitymark: Dunya , 1997.ok

PRADO, Amaya O. M. de Almeida. Dom Quixote das crianças e de Lobato. In: LAJOLO, Marisa; CECCANTINI, João Luís (org.). Monteiro Lobato, livro a livro: obra infantil. São Paulo: UNESP; Imprensa Oficial do Estado de São Paulo, 2008.ok SILVEIRA, Magno. Ilustradores de Lobato: a construção do livro infantil brasileiro1920-1948. São José dos Campos: SESC, 2015.

VIEIRA, Adriana Silene. Um inglês no sítio de Dona Benta: estudo da apropriação de Peter Pan na obra lobatiana. Dissertação (Mestrado em Teoria Literária). Instituto de Estudos da Linguagem -IEL. Universidade Estadual de Campinas, UNICAMP, 1998. 
